\title{
Predictors of distant metastasis on exploration in patients with potentially resectable pancreatic cancer
}

Xinchun Liu' ${ }^{1,2+} \mathbb{D}$, Yue Fu ${ }^{1,3+}$, Qiuyang Chen ${ }^{1,2}$, Junli Wu ${ }^{1,2}$, Wentao Gao ${ }^{1,2}$, Kuirong Jiang ${ }^{1,2}$, Yi Miao ${ }^{1,2^{*}}$ and Jishu Wei $\mathrm{i}^{1,2^{*}}$

\begin{abstract}
Background: Patients with potentially resectable pancreatic ductal adenocarcinoma (PDAC) are frequently found to be unresectable on exploration due to small distant metastasis. This study was to investigate predictors of small distant metastasis in patients with potentially resectable PDAC.

Methods: Patients who underwent surgical exploration for potentially resectable PDAC from 2013 to 2014 were reviewed retrospectively and divided into two groups according to whether distant metastases were encountered on exploration. Then, univariate and multivariate logistic regression analyses were used to identify predictors of distant metastasis. A scoring system to predict distant metastasis of PDAC on exploration was constructed based on the regression coefficient of a multivariate logistic regression model.

Results: A total of 235 patients were included in this study. Mean age of the study population was $61.7 \pm 10.4$ years old. Upon exploration, distant metastases were found intraoperatively in 62 (26.4\%) patients, while the remaining 173 were free of distant metastases. Multivariate logistic regression analysis identified that age $\leq 62$ years old $(p<0.001)$, male sex $(p=0.011)$, tumor size $\geq 4.0 \mathrm{~cm}(p<0.001)$, alanine aminotransferase level (ALT) $<125 \mathrm{U} / \mathrm{L}(p<0.001)$, and carbohydrate antigen (CA19-9) level $\geq 385 \mathrm{U} / \mathrm{mL}(p<0.001)$ were independent risk factors for occult distant metastasis of PDAC. A preoperative scoring system (0-8 points) for distant metastasis on exploration was constructed using these five factors. The receiver operating characteristic curves showed that the area under the curve of this score was 0.85 . A score of 6 points was suggested to be the optimal cut-off value, and the sensitivity and specificity were $85 \%$ and $69 \%$, respectively.
\end{abstract}

Conclusions: Distant metastasis is still frequently encountered on exploration for patients with potentially resectable PDAC. Younger age, male sex, larger tumor size, low ALT level and high CA19-9 level are independent predictors of unexpected distant metastasis on exploration.

Keywords: Distant metastasis, Pancreatic cancer, Predictive factor, Surgical exploration

\section{Background}

Pancreatic ductal adenocarcinoma (PDAC) is one of the most dismal malignancies with an overall 5-year survival rate of $<7 \%[1,2]$. Despite enormous efforts directed at the treatment of PDAC, radical resection remains the most effective treatment modality, and it increases the

\footnotetext{
* Correspondence: miaoyi@njmu.edu.cn; weijishu@njmu.edu.cn

${ }^{+}$Xinchun Liu and Yue Fu contributed equally to this work.

${ }^{1}$ Pancreas Center, The First Affiliated Hospital of Nanjing Medical University,

300 Guangzhou Road, Nanjing, Jiangsu Province, China

Full list of author information is available at the end of the article
}

5-year survival rate for PDAC patients to $10-25 \%$ [3-5]. However, due to a lack of presentations at early stages and the aggressive nature of this disease, the majority of PDAC patients present an unresectable disease at the time of diagnosis, and only around $20 \%$ of newly diagnosed PDAC patients were suitable candidates for curable surgical resection [6].

Multidetector computed tomography (MDCT) is currently the optimal imaging modality for preoperative diagnosis and staging of PDAC [7, 8]. However, this imaging modality has a poor sensitivity for identifying

(C) The Author(s). 2018 Open Access This article is distributed under the terms of the Creative Commons Attribution 4.0 International License (http://creativecommons.org/licenses/by/4.0/), which permits unrestricted use, distribution, and 
small liver or peritoneal metastasis [7, 9]. Among the patients subjected to surgical exploration, a significant proportion $(40 \%)$ of them are found to be unresectable due to occult distant metastasis or infiltration of local structures [10-12]. The proportion of patients successfully resected during surgical exploration might be as low as $50 \%[12,13]$.

For patients with distant occult metastasis, surgical resection is unnecessary as it does not prolong survival in the overwhelming majority of patients $[14,15]$. Besides, unnecessary surgical exploration often delays administration of other treatments, for example systematic chemotherapy, which currently is the preferred treatment for metastatic PDAC patients [16]. Therefore, it is important to differentiate PDAC patients with distant metastasis from those with truly resectable cancers to avoid unnecessary surgery and offer these patients tailored treatments in a timely manners. The objective of this retrospective study was to analyze the predictive factors for distant occult metastasis in patients with resectable PDAC based on preoperative MDCT.

\section{Methods}

\section{Study design and patients}

This was a single institution, retrospective study, from a high-volume center, the Pancreas Center, The First Affiliated Hospital of Nanjing Medical University, China. All patients who underwent elective pancreatic surgery at our unit between January 2014 and December 2015 were reviewed retrospectively. Only patients with a final diagnosis of PDAC were included. Exclusion criteria were as follows: 1) patients underwent an operation with palliative intent, 2) patients without preoperative internal MDCT, and 3) patients with distant metastasis detected with preoperative MDCT. All patients underwent a triple-phase 16-row MDCT, consisting of unenhanced, early arterial, and venous phases.

Patients were included in the "with metastasis" (WM) group when distant metastasis, such as liver and peritoneal metastasis, was encountered during surgery. The remaining patients were included in the "no metastasis" (NM) group. During the surgery, distant metastasis was discovered through manual palpation by experienced surgeons and further confirmed with frozen resection. Intra-operative ultrasound was not used.

Data collected included age at diagnosis; sex; drinking and smoking history; comorbidities (Hypertension and Diabetes Mellitus); chief complaint (with pain or without pain); preoperative laboratory data, such as alanine aminotransferase (ALT), aspartate aminotransferase (AST), total bilirubin (TBil), direct bilirubin (DBil), albumin, alpha fetoprotein (AFP), carbohydrate antigen (CA199), and carcinoembryonic antigen (CEA); tumor size and location on MDCT; and time interval between MDCT and operation. The possible risk factors for distant metastasis were then examined statistically. Data were obtained from the patients' medical records and the hospital electronic database. All the imaging results were reviewed by a dedicated radiologist. This study was approved by the institutional review board with a waiver of informed consent (No. 2016-SR-210).

\section{Statistical analysis}

Quantitative variables are presented as the mean \pm standard deviation and qualitative variables are expressed as absolute and relative frequencies. Comparisons between the WM and NM groups are performed using the Student's $t$-test or Chi-square test accordingly. The association between the predictive factors and presence of distant metastasis was first evaluated by univariate logistic regression. Factors with a $p<0.1$ in the univariate regression analysis were included in multivariate logistic regression analysis. Backward stepwise elimination was used to exclude variables with $p>0.05$ from the model. Continuous variables were divided into two groups according to the mean value of each parameter. All statistical analyses were performed using Stata/SE version 10.0 for Windows (StataCorp, Texas, USA). All tests for significance were two-sided and a value of $p<0.05$ was considered statistically significant.

\section{Results}

\section{Demographic and clinicopathologic characteristics}

In the study period, a consecutive series of 501 patients with PDAC underwent laparotomy in our center. Of these, 26 patients were excluded because they had unresectable disease detected radiologically and underwent an operation with palliative intent. Another 240 patients were excluded for having no internal MDCT: 218 didn't have any image studies in our hospital, and 22 had only Magnetic Resonance Imaging or magnetic resonance cholangiopancreatography or positron emission tomography/computed tomography other than MDCT. Ultimately, a total of 235 patients were included in the analysis (Fig. 1).

All the included 235 patients underwent upfront surgery, and received no neoadjuvant therapy. Distant metastasis was found in $62(26.4 \%)$ patients, including 31 liver metastases and 31 peritoneal metastases. Of the 62 patients with metastases, three patients underwent pancreaticoduodenectomy for primary cancer and the remaining patients underwent different palliative procedures accordingly. Of the $173 \mathrm{NM}$ patients, 164 patients underwent resection successfully and 9 patients underwent palliative operations because the tumor was locally advanced. Details of the procedures are shown in Table 1. 


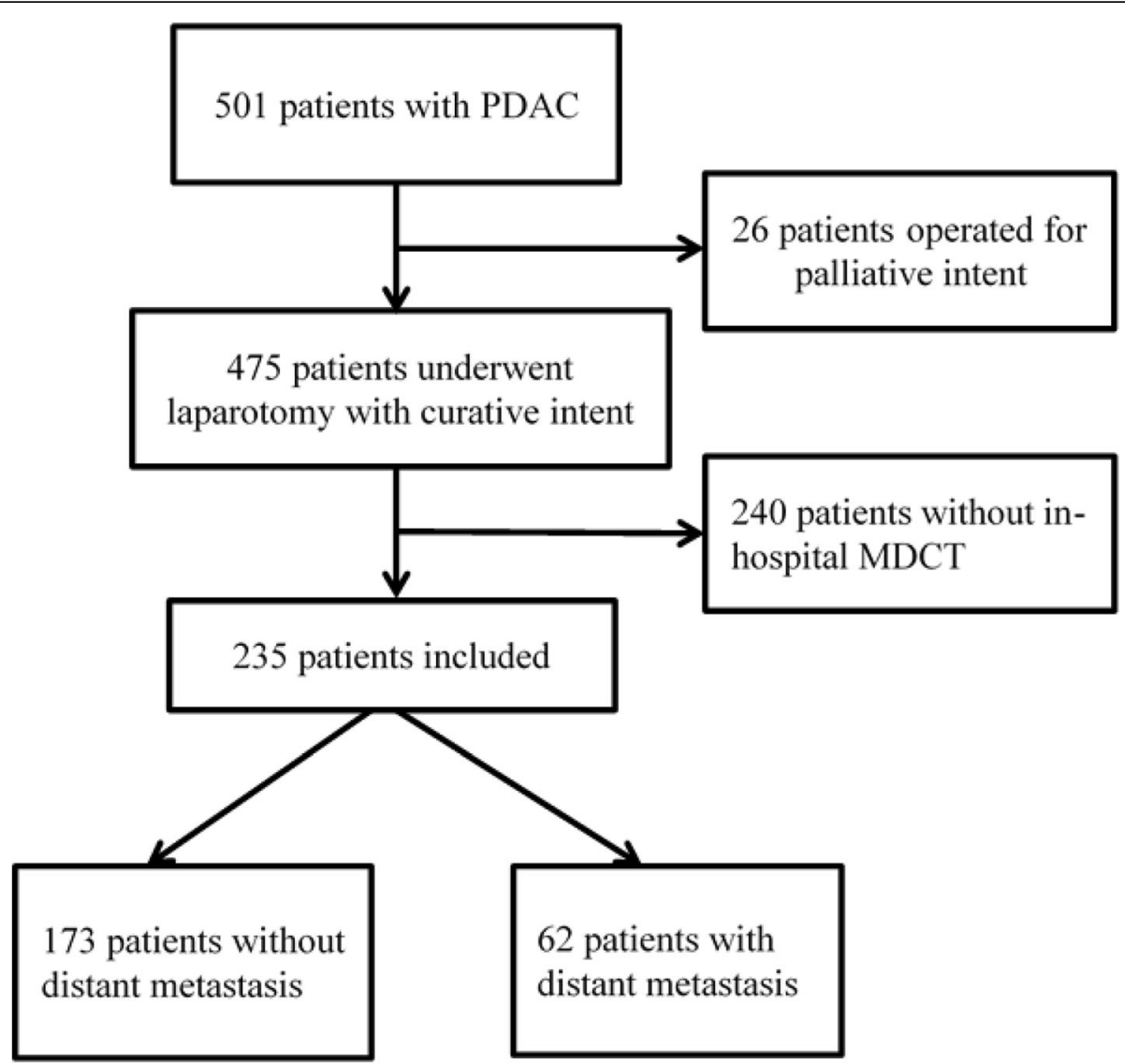

Fig. 1 Flow diagram showing selection of patients for inclusion in the study

Comparisons between the patients with metastasis (WM) and patients with no metastasis (NM)

Patients' demographics and laboratory values at the time of diagnosis are shown in Table 2. The mean age of all patients was $61.7 \pm 10.4$ years (median 62 years, range 2987 years $)$, and $64.3 \%(n=151)$ were male. The metastasis

Table 1 Procedures performed for 235 patients

\begin{tabular}{lccc}
\hline & $\begin{array}{c}\text { Total } \\
(n=235)\end{array}$ & $\begin{array}{c}\text { No Metastasis } \\
(n=173)\end{array}$ & $\begin{array}{c}\text { With Metastasis } \\
(n=62)\end{array}$ \\
\hline Resected & 167 & 164 & 3 \\
PD/PPPD & 124 & 121 & 3 \\
Distal pancreatectomy & 39 & 39 & 0 \\
Total pancreatectomy & 1 & 1 & 0 \\
Appleby Operation & 3 & 3 & 0 \\
Not Resected & 68 & 9 & 59 \\
Double Bypass & 13 & 1 & 12 \\
Biliary Bypass & 9 & 4 & 5 \\
Gastric Bypass & 4 & 0 & 4 \\
Celiac plexus neurolysis & 16 & 0 & 16 \\
Exploration alone & 26 & 4 & 22 \\
\hline
\end{tabular}

PD pancreaticoduodenectomy, PPPD

pylorus-preserving pancreaticoduodenectomy group had a younger age (59.4 vs. 62.5 years, $p=0.041)$ and larger tumor size compared with the NM group (4.2 vs. $3.8 \mathrm{~cm}, p<0.001)$. Additionally, patients in the NM group had a higher ALT level $(p=0.010)$ and a higher AST level $(p=0.010)$ when compared with patients in the WM group. Levels of TBil and DBil in the WM group were found to be lower than those in the NM group; however, these differences were not significant $(p=0.057$ and 0.085 , respectively).

\section{Predictive factors for occult distant metastases on exploration}

Table 3 summarizes the univariate and multivariate logistic regression analyses of the risk factor for distant metastasis using the significant univariate predictors. In univariate analyses, significant predictive factors for finding distant metastasis during surgery were younger age $(p=0.003)$, larger tumor size $(p<0.001)$, tumor location $(p=0.048)$, lower ALT level $(p<0.001)$, lower AST level $(p=0.006)$, lower TBil level $(p<0.019)$, higher CA199 level $(p=0.007)$, and higher CEA level $(p<0.001)$ (Table 3$)$. In multivariate analysis, the following variables remained significantly associated with presence of distant metastasis: an age $<62$ years old (Odds ratio $(\mathrm{OR})=3.97$; 95\% Confidence interval (CI): 1.87-8.42; $p<0.001)$, male sex (OR = 
Table 2 Demographic and clinical characteristics of included patients

\begin{tabular}{|c|c|c|c|c|}
\hline & $\begin{array}{c}\text { Total } \\
(n=235)\end{array}$ & $\begin{array}{c}\text { NM } \\
(n=173)\end{array}$ & $\begin{array}{c}\text { WM } \\
(n=62)\end{array}$ & $p$ \\
\hline Age (years) (mean \pm SD) & $61.7 \pm 10.4$ & $62.5 \pm 10.4$ & $59.4 \pm 10.0$ & 0.041 \\
\hline Sex, male/female & $151 / 84$ & $105 / 68$ & $46 / 16$ & 0.057 \\
\hline \multicolumn{5}{|l|}{ Chief complaint } \\
\hline Pain & 150 & 106 & 44 & \multirow[t]{2}{*}{0.173} \\
\hline Without pain & 85 & 67 & 18 & \\
\hline Jaundice & 73 & 61 & 12 & \multirow[t]{2}{*}{0.200} \\
\hline Without jaundice & 162 & 112 & 50 & \\
\hline Weight loss & 100 & 70 & 30 & \multirow[t]{2}{*}{0.279} \\
\hline Without weight loss & 135 & 103 & 32 & \\
\hline \multicolumn{5}{|l|}{ Personal history } \\
\hline Smoking, yes/no & $48 / 187$ & $34 / 139$ & $14 / 48$ & 0.624 \\
\hline Drinking, yes/no & $38 / 197$ & $32 / 141$ & $6 / 56$ & 0.106 \\
\hline Hypertension, yes/no & $71 / 164$ & $51 / 122$ & $20 / 42$ & 0.683 \\
\hline Diabetes, yes/no & $36 / 199$ & $25 / 148$ & $11 / 51$ & 0.537 \\
\hline Interval between imaging and surgery, days & $6.3 \pm 4.8$ & $6.3 \pm 4.6$ & $6.2 \pm 5.2$ & 0.868 \\
\hline Tumor size on MDCT (cm) & $4.2 \pm 1.9$ & $3.8 \pm 1.6$ & $5.5 \pm 2.0$ & $<0.001$ \\
\hline \multicolumn{5}{|l|}{ Tumor location } \\
\hline Head & 174 & 134 & 40 & \multirow[t]{2}{*}{0.046} \\
\hline Body or tail & 61 & 39 & 22 & \\
\hline \multicolumn{5}{|l|}{ Laboratory examinations } \\
\hline ALT & $124.6 \pm 173.1$ & $142.2 \pm 179.1$ & $75.9 \pm 146.1$ & 0.010 \\
\hline AST & $84.3 \pm 100.5$ & $94.4 \pm 105.0$ & $56.3 \pm 81.2$ & 0.010 \\
\hline TBil & $73.9 \pm 103.8$ & $81.6 \pm 107.6$ & $52.4 \pm 89.5$ & 0.057 \\
\hline DBil & $50.3 \pm 74.6$ & $55.4 \pm 77.2$ & $36.3 \pm 65.7$ & 0.085 \\
\hline ALB & $40.0 \pm 5.4$ & $40.1 \pm 5.4$ & $39.7 \pm 5.2$ & 0.686 \\
\hline AFP & $2.9 \pm 1.8$ & $2.8 \pm 1.4$ & $3.1 \pm 2.6$ & 0.293 \\
\hline CA19-9 & $385.5 \pm 378.8$ & $335.7 \pm 350.2$ & $525.2 \pm 422.0$ & $<0.001$ \\
\hline CEA & $8.9 \pm 20.3$ & $8.1 \pm 21.9$ & $11.1 \pm 14.7$ & 0.328 \\
\hline
\end{tabular}

2.79, 95\% CI: 1.26-6.19; $p=0.011$ ), a tumor size $\geq 4.0 \mathrm{~cm}$ $(\mathrm{OR}=16.02,95 \%$ CI: 5.31-48.30; $p<0.001)$, ALT level $<$ $125 \mathrm{U} / \mathrm{L}(\mathrm{OR}=6.19,95 \% \mathrm{CI}: 2.26-16.92, p<0.001)$, and a CA19-9 level $\geq 385$ U/ml (OR = 3.53, 95\% CI: 1.87-6.67; $p$ $<0.001$ ) (Table 3).

The five independent risk factors found in the multivariate analysis were used to develop a score system based on the regression coefficient of the multivariate logistic regression model (Table 4). The score values for individual patient ranged from 0 to 8 . The risk of patients with distant metastasis progressively increased as the score increased (Table 5, Fig. 2a). A receiver operating characteristic curve of the model showed that the area under curve of this score was 0.85 (95\% CI: 0.80-0.89) (Fig. 2b). A score of 6 points was suggested to be the optimal cut-off value (Youden index $=0.548$ ) to divide the risk strata with a sensitivity of $85 \%$ and a specificity of $69 \%$.

\section{Discussion}

Currently, radical resection provides the only chance for long-term survival for patients with PDAC. As surgical skills and perioperative management developed, mortality after pancreatic surgery has dramatically decreased to less than 5\% [17]. However, morbidity after pancreatic surgery is still very high. Non-curative exploratory laparotomy of pancreas can have a morbidity as high as 42.3\% and does not increase survival [18]. Moreover, this unnecessary operation can postpone other more suitable therapies such as chemotherapy and can become the last straw to their debilitating state.

Unfortunately, not all patients with PDAC who undergo resection surgery can be resected successfully. Despite thorough pre-operative staging with advanced imaging techniques, incidental occult distant metastasis from PDAC is commonly encountered in during surgery 
Table 3 Univariate and multivariate analyses of factors predicting distant metastases

\begin{tabular}{|c|c|c|c|c|c|c|c|c|}
\hline & & \multirow{2}{*}{$\begin{array}{c}\text { Total } \\
n=235\end{array}$} & \multirow{2}{*}{$\begin{array}{c}\text { NM } \\
n=173\end{array}$} & \multirow{2}{*}{$\begin{array}{c}\text { WM } \\
n=62\end{array}$} & \multicolumn{2}{|c|}{ Univariate analysis } & \multicolumn{2}{|c|}{ Multivariate analysis ${ }^{a}$} \\
\hline & & & & & $p$ & OR $(95 \% \mathrm{Cl})$ & $p$ & OR (95\% Cl) \\
\hline \multirow[t]{2}{*}{ Age } & $>62$ & 115 & 95 & 20 & 0.003 & 1 & $<0.001$ & 1 \\
\hline & $\leq 62$ & 120 & 78 & 42 & & $2.55(1.39,4.71)$ & & $3.97(1.87,8.42)$ \\
\hline \multirow[t]{2}{*}{ Sex } & Female & 84 & 68 & 16 & 0.057 & 1 & 0.011 & 1 \\
\hline & Male & 151 & 105 & 46 & & $1.86(0.98,3.55)$ & & $2.79(1.26,6.19)$ \\
\hline \multirow[t]{2}{*}{ Pain } & No & 85 & 67 & 18 & 0.174 & 1 & & \\
\hline & Yes & 150 & 106 & 44 & & $1.50(0.82,2.90)$ & & \\
\hline \multirow[t]{2}{*}{ Jaundice } & No & 162 & 112 & 50 & 0.022 & 1 & & \\
\hline & Yes & 73 & 61 & 12 & & $0.44(0.22,0.89)$ & & \\
\hline \multirow[t]{2}{*}{ Weight loss } & No & 135 & 103 & 32 & 0.280 & 1 & & \\
\hline & Yes & 100 & 70 & 30 & & $1.37(0.77,2.47)$ & & \\
\hline \multirow[t]{2}{*}{ Smoking } & No & 187 & 139 & 48 & 0.624 & 1 & & \\
\hline & Yes & 48 & 34 & 14 & & $1.19(0.59,2.41)$ & & \\
\hline \multirow[t]{2}{*}{ Drinking } & No & 197 & 141 & 56 & 0.112 & 1 & & \\
\hline & Yes & 38 & 32 & 6 & & $0.47(0.19,1.19)$ & & \\
\hline \multirow[t]{2}{*}{ Hypertension } & No & 71 & 51 & 20 & 0.683 & 1 & & \\
\hline & Yes & 164 & 122 & 42 & & $1.14(0.61,2.13)$ & & \\
\hline \multirow[t]{2}{*}{ Diabetes } & No & 199 & 148 & 51 & 0.538 & 1 & & \\
\hline & Yes & 36 & 25 & 11 & & $1.28(0.59,2.78)$ & & \\
\hline \multirow[t]{3}{*}{ Interval between imaging and surgery } & $\leq 7$ & 170 & 123 & 47 & & 1 & & \\
\hline & $7-14$ & 48 & 39 & 9 & 0.213 & $0.60(0.27,1.34)$ & & \\
\hline & $\geq 14$ & 17 & 11 & 6 & 0.461 & $1.49(0.52,4.31)$ & & \\
\hline \multirow[t]{2}{*}{ Tumor size } & $<4.0$ & 96 & 92 & 4 & $<0.001$ & 1 & $<0.001$ & 1 \\
\hline & $\geq 4.0$ & 139 & 81 & 58 & & $16.47(5.73,47.36)$ & & $16.02(5.31,48.30)$ \\
\hline \multirow[t]{2}{*}{ Tumor location } & Head & 174 & 134 & 40 & 0.048 & 1 & & \\
\hline & Body/tail & 61 & 39 & 22 & & $1.88(1.01,3.55)$ & & \\
\hline \multirow[t]{2}{*}{ ALT } & $\geq 125$ & 71 & 64 & 7 & $<0.001$ & 1 & $<0.001$ & 1 \\
\hline & $<125$ & 164 & 109 & 55 & & $4.61(1.98,10.74)$ & & $6.19(2.26,16.92)$ \\
\hline \multirow[t]{2}{*}{ AST } & $\geq 85$ & 75 & 64 & 11 & 0.006 & 1 & & \\
\hline & $<85$ & 160 & 109 & 51 & & $2.72(1.32,5.60)$ & & \\
\hline \multirow[t]{2}{*}{ TBil } & $\geq 75$ & 78 & 65 & 13 & 0.019 & 1 & & \\
\hline & $<75$ & 157 & 108 & 49 & & $2.27(1.14,4.50)$ & & \\
\hline \multirow[t]{2}{*}{ DBil } & $\geq 50$ & 75 & 61 & 14 & 0.069 & 1 & & \\
\hline & $<50$ & 160 & 112 & 48 & & $1.87(0.95,3.66)$ & & \\
\hline \multirow[t]{2}{*}{ ALB } & $\geq 40$ & 124 & 89 & 35 & 0.498 & 1 & & \\
\hline & $<40$ & 111 & 84 & 27 & & $0.82(0.46,1.47)$ & & \\
\hline \multirow[t]{2}{*}{ AFP } & $<3.0$ & 153 & 111 & 42 & 0.612 & 1 & & \\
\hline & $\geq 3.0$ & 82 & 62 & 20 & & $0.85(0.46,1.57)$ & & \\
\hline CA19-9 & $<385$ & 144 & 115 & 29 & 0.007 & 1 & 0.015 & 1 \\
\hline & $\geq 385$ & 91 & 58 & 33 & & $2.26(1.25,4.07)$ & & $2.49(1.19,5.21)$ \\
\hline CEA & $<9$ & 183 & 145 & 38 & $<0.001$ & 1 & & \\
\hline & $\geq 9$ & 52 & 28 & 24 & & $3.53(1.87,6.67)$ & & \\
\hline
\end{tabular}


Table 4 Predictive scoring system for pancreatic fistula

\begin{tabular}{lcc}
\hline Preoperative factor & $\beta$ coefficient & Points contributed \\
\hline Age & & 0 point \\
$>62$ years old & 1.38 & 1 point \\
$\leq 62$ years old & & \\
Sex & & 0 point \\
$\quad$ Female & 1.02 & 1 point \\
Male & & \\
Tumor size & & 0 point \\
$<4.0 \mathrm{~cm}$ & 2.78 & 3 points \\
$\geq 4.0 \mathrm{~cm}$ & & 0 point \\
ALT & & 2 points \\
$\geq 125 \mathrm{U} / \mathrm{L}$ & 1.89 & \\
$<125 \mathrm{U} / \mathrm{L}$ & & 0 point \\
$\mathrm{CA} 19-9$ & & 1 point \\
$<385 \mathrm{U} / \mathrm{mL}$ & &
\end{tabular}

[19]. Previous studies revealed that up to $31 \%$ of patients with resectable PDAC staged by MDCT were found to have metastases in sbusequent laparotomy or staging laparoscopy [8, 20-22]. In patients with locally advanced PDAC, the likelihood of finding unresectable PDAC at operation is much higher [23].

Despite the emerging use of magnetic resonance imaging, endoscopic ultrasound, and positron emission tomography/computed tomography, MDCT remains the most commonly used imaging modality for the diagnosis and staging of PDAC [7, 24, 25]. However, small distant metastases, such as minimal peritoneal deposits and small liver metastases, can remain undetected even with modern computed tomography protocols [26]. Previous studies suggested that patients with PDAC should undergo the operation within 25 or 32 days of diagnostic imaging to reduce the risk of tumor progression to unresectable disease $[27,28]$. In the present study, we found that $26 \%$ of the patients selected for curative surgery for PDAC had distant metastasis. However, in our study, we found no affects attributable to the time interval between MDCT study and surgery on the accuracy of MDCT in determining the presence or absence of metastatic disease.

Due to the limitation of imaging, other techniques were reported in literature for determining the resectability of PDAC. One such technique is peritoneal lavage cytology (PLC), which is a routinely applied in the diagnosis and staging of several cancers. However, in PDAC, although a positive PLC represents an early recurrence and a worse prognosis, a positive PLC is not regarded as equal to a macrometastasis in patients with PDAC and it does not exclude a curative resection in patients without other distant metastasis [29-31]. Another technique is staging laparoscopy, which has been used to diagnose occult metastasis to decrease the number of unnecessary laparotomies in PDAC [32-34]. Patients who were found to harbor distant metastasis by laparoscopy staging received palliative chemotherapy earlier and lived longer than patients who underwent only laparotomy [33]. Moreover, a cost analysis indicated that use of laparoscopy in pancreatic cancer did not significantly increase the overall expense of treatment [34]. A recent review of 1146 patients found that diagnostic laparoscopy prior to laparotomy could decrease the rate of unnecessary laparotomy from 40 to $20 \%$ in patients with periampullary cancer [10]. As a minimally invasive modality, staging laparoscopy was suggested to be routinely used to identify radiographically occult metastases and prevent rewardless laparotomies [20, 21, 35, 36]. However, as the proportion of patients found to have metastases at laparoscopy is decreasing, its routine use is challenged, and some studies have investigated the indications for selective use of staging laparoscopy in pancreatic cancer [37]. Identifying patients at an increased risk of distant

Table 5 Risk of distant metastasis for patients with each score

\begin{tabular}{|c|c|c|c|c|c|c|c|}
\hline \multirow[t]{2}{*}{ Score } & \multicolumn{2}{|c|}{ No. of patients } & \multirow[t]{2}{*}{$\%$} & \multirow[b]{2}{*}{ Sensitivity (\%) } & \multirow[b]{2}{*}{ Specificity (\%) } & \multirow[b]{2}{*}{ Accuracy (\%) } & \multirow[b]{2}{*}{ Youden Index (\%) } \\
\hline & Total & WM & & & & & \\
\hline 0 & 5 & 0 & 0 & 100 & 0 & 26.38 & 0 \\
\hline 1 & 17 & 0 & 0 & 100 & 2.89 & 28.51 & 2.89 \\
\hline 2 & 20 & 0 & 0 & 100 & 12.72 & 35.74 & 12.72 \\
\hline 3 & 26 & 1 & 3.85 & 100 & 24.28 & 44.26 & 24.28 \\
\hline 4 & 38 & 4 & 10.53 & 98.39 & 38.73 & 54.47 & 37.12 \\
\hline 5 & 23 & 4 & 17.39 & 91.94 & 58.38 & 67.23 & 50.32 \\
\hline 6 & 51 & 16 & 31.37 & 85.48 & 69.36 & 73.62 & 54.84 \\
\hline 7 & 41 & 26 & 63.41 & 59.68 & 89.60 & 81.70 & 49.28 \\
\hline 8 & 14 & 11 & 78.57 & 17.74 & 98.27 & 77.02 & 16.01 \\
\hline
\end{tabular}



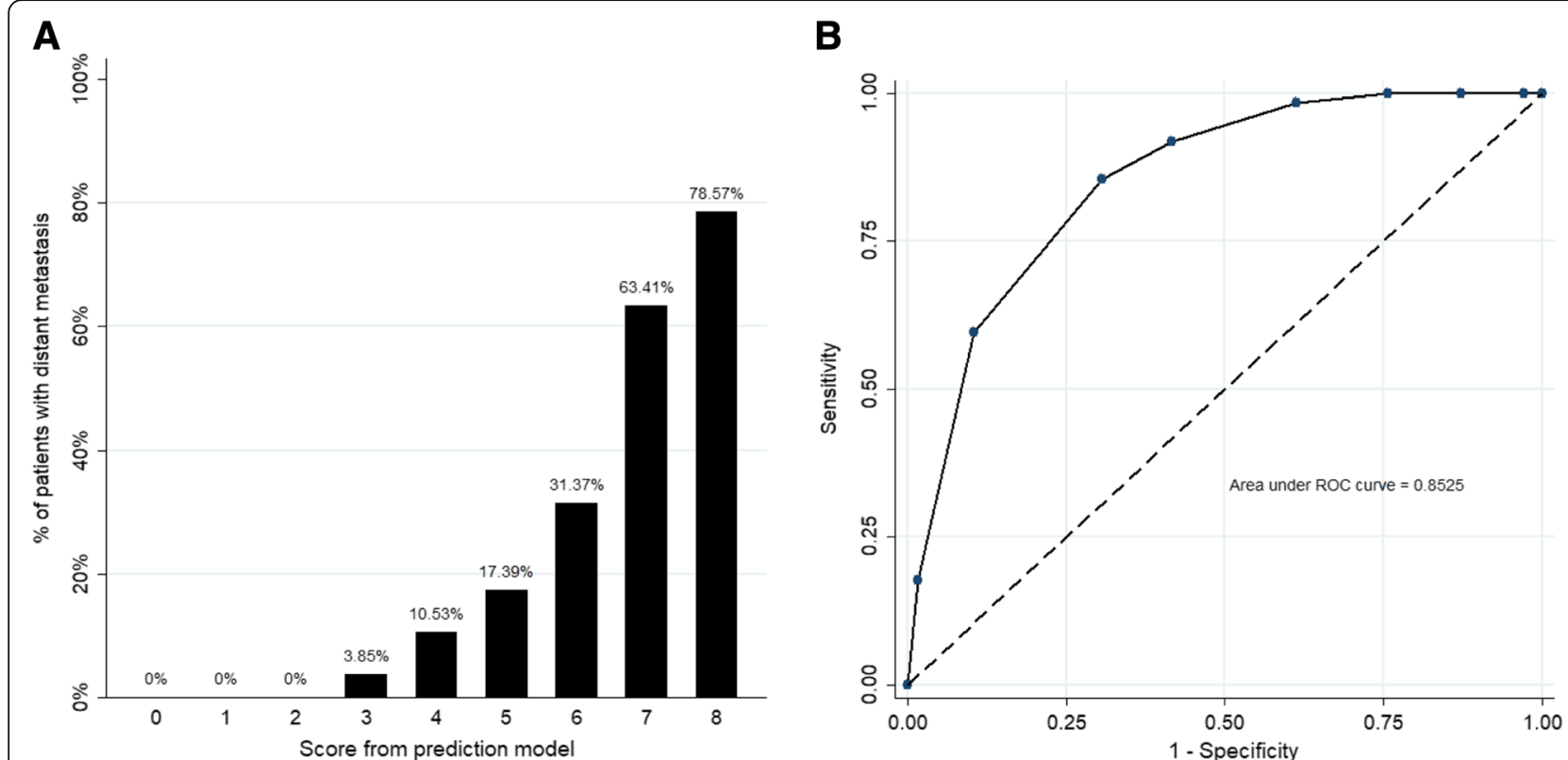

Fig. 2 Prediction of distant metastasis. a Proportion of patients with occult metastasis during laparotomy. b Receiver operating characteristics of number of factors to predict the risk for distant metastasis found at operation

metastasis seems to be a more reasonable approach, that can increase the diagnostic accuracy of staging laparoscopy and deliver optimal disease management.

By comparing a number of preoperative factors, this study identified that young age, male sex, low ALT level, large tumor size, and high CA 19-9 level were independent predictors of distant metastases in patients with resectable PDAC. Previous studies found that tumors in the pancreas body and tail, tumor size as determined by MDCT, serum CA 19-9 level, CEA, and weight loss were risk factors for unresectability in patients with potentially resectable PDAC $[20,38-41]$. Our study confirmed that tumor in the body and tail, and high CEA were associated with distant metastasis in univariate analysis, but not in multivariate analysis. Weight loss was not associated with distant metastasis. In line with previous studies, CA19-9 and tumor size were independent predictive factors for distant metastasis [37]. Ong et al. found that age $<=65$ was a predictive factor of resectable disease [42]. On the contrary, our study found that age $<=62$ was an independent risk factor of distant metastasis. Also, we found that patients with distant metastatic PDAC had significantly lower levels of ALT and AST than patients without distant metastatic PDAC, which might be explained by the following reasons. First, this might be relevant to the population characteristics in our study. For example, all our patients underwent upfront surgery without neoadjuvant chemotherapy, which has liver toxicity and results in elevated levels of ALT and AST. Second, we found that patients with lower ALT levels are more likely to be without jaundice, which, on the one hand is beneficial for liver function, but on the other hand may lead to late diagnosis of PDAC due to lack of symptoms. Third, we found that patients with peritoneal metastases had a slightly lower ALT level than patients with liver metastasis $(52.7 \pm$ 139.1 vs $99.2 \pm 151.3 \mathrm{U} / \mathrm{L}, p=0.212$ ). This implies that liver metastasis could only slightly raise the level of ALT when there are no other contributing factors.

After identifying the risk factors associated with distant metastasis, this study developed a model for predicting occult distant metastasis in patients undergoing non-curative laparotomy for potentially resectable PDAC. When a score of 6 points was taken as the cut-off value, this score system had a sensitivity of $85 \%$ and a specificity of $69 \%$. However, it is necessary to point out that the reliability and effectiveness of this score system still needs validation by further studies. Also, because successful resection is the only cure for PDAC, these preoperative predictors alone are not contraindications for pancreatic exploration. The predictive factors identified in this study only indicated that additional preoperative staging modalities, such as selective staging laparoscopy, may be needed before laparotomy is indicated.

This study has several limitations. First, due to the nature of its retrospective design, there was a potential for several biases. For example, small intrahepatic lesions may be missed by palpation. Second, the sample size of the present study is relatively small. Therefore, a well-designed, prospective study with more data will be needed to validate the results of this study. Third, though staging laparoscopy was discussed and suggested 
in this study, we had limited experience in using it. Lastly, although neoadjuvant therapy has become increasingly common in the practice, our findings may not apply to this group of patients.

\section{Conclusions}

In conclusion, we showed that for patients with potentially resectable PDAC based on MDCT, distant metastasis is still frequently encountered during surgery. Younger age, male sex, large tumor size, lower ALT and higher CA19-9 are independent predictive factors for finding distant metastasis during exploration.

\section{Abbreviations}

ALT: Alanine aminotransferase; AST: Aspartate aminotransferase; CA199: Carbohydrate antigen; CEA: Carcinoembryonic antigen; DBil: Direct bilirubin; MDCT: Multidetector computed tomography; NM: No metastasis; PDAC: Pancreatic ductal adenocarcinoma; PLC: Periton eal lavage cytology; TBil: Total bilirubin; WM: With metastasis

\section{Acknowledgements}

Not applicable

\section{Funding}

This work was supported by the Natural Science Foundation of China (81672449); Natural Science Foundation of Jiangsu Province (BK20161590); and the International Exchange and Cooperation Projects of Nanjing Medical University (C046). The founding resources had no role in study design, data collection and analysis, preparation of the manuscript, or decision to publish.

\section{Availability of data and materials}

All data in our study are available from the corresponding authors upon reasonable request.

\section{Authors' contributions}

Study conception and design of the study: XL, JuW, WG, KJ, YM, and JiW. Acquisition of data: YF, and QC. Statistical analysis and interpretation of data: $\mathrm{XL}$ and YF. Drafting of the manuscript: $X \mathrm{~L}$, and JiW. Critical revision: YF, QC, JuW, WG, KJ, and YM. Approval of the final version: all authors.

\section{Ethics approval and consent to participate}

This study was approved by the institutional review board at The First Affiliated Hospital of Nanjing Medical University (No. 2016-SR-210). Due to the retrospective nature of this study and all data was retrieved from medical records without additional blood samples or biochemical analysis, informed consent from individual participants was waived.

\section{Consent for publication}

Not applicable

\section{Competing interests}

The authors declare that they have no competing interests.

\section{Publisher's Note}

Springer Nature remains neutral with regard to jurisdictional claims in published maps and institutional affiliations.

\section{Author details}

${ }^{1}$ Pancreas Center, The First Affiliated Hospital of Nanjing Medical University, 300 Guangzhou Road, Nanjing, Jiangsu Province, China. ${ }^{2}$ Pancreas Institute, Nanjing Medical University, Nanjing, China. ${ }^{3}$ Department of Gastrointestinal Surgery, The Affiliated Changzhou No.2 People's Hospital of Nanjing Medical University, Changzhou, China.
Received: 6 August 2018 Accepted: 23 October 2018

Published online: 06 November 2018

\section{References}

1. Waddell N, Pajic M, Patch AM, Chang DK, Kassahn KS, Bailey P, Johns AL, Miller D, Nones K, Quek K, et al. Whole genomes redefine the mutational landscape of pancreatic cancer. Nature. 2015;518(7540):495-501.

2. Siegel RL, Miller KD, Jemal A. Cancer statistics, 2016. CA Cancer J Clin. 2016; 66(1):7-30.

3. Perysinakis I, Avlonitis S, Georgiadou D, Tsipras H, Margaris I. Five-year actual survival after pancreatoduodenectomy for pancreatic head cancer. ANZ J Surg. 2015;85(3):183-6

4. Schnelldorfer T, Ware AL, Sarr MG, Smyrk TC, Zhang L, Qin R, Gullerud RE, Donohue JH, Nagorney DM, Farnell MB. Long-term survival after pancreatoduodenectomy for pancreatic adenocarcinoma: is cure possible? Ann Surg. 2008;247(3):456-62.

5. Sener SF, Fremgen A, Menck HR, Winchester DP. Pancreatic cancer: a report of treatment and survival trends for 100,313 patients diagnosed from 19851995, using the National Cancer Database. J Am Coll Surg. 1999;189(1):1-7.

6. Speer AG, Thursfield VJ, Torn-Broers $Y$, Jefford M. Pancreatic cancer: surgical management and outcomes after 6 years of follow-up. Med J Aust. 2012; 196(8):511-5.

7. Pietryga JA, Morgan DE. Imaging preoperatively for pancreatic adenocarcinoma. J Gastrointest Oncol. 2015;6(4):343-57.

8. Loizou L, Albiin N, Leidner B, Axelsson E, Fischer MA, Grigoriadis A, Del Chiaro M, Segersvärd R, Verbeke C, Sundin A, Kartalis N. Multidetector CT of pancreatic ductal adenocarcinoma: Effect of tube voltage and iodine load on tumour conspicuity and image quality. Eur Radiol. 2016;26(11):4021-4029.

9. Vargas R, Nino-Murcia M, Trueblood W, Jeffrey RB Jr. MDCT in pancreatic adenocarcinoma: prediction of vascular invasion and resectability using a multiphasic technique with curved planar reformations. AJR Am J Roentgenol. 2004;182(2):419-25.

10. Allen VB, Gurusamy KS, Takwoingi Y, Kalia A, Davidson BR. Diagnostic accuracy of laparoscopy following computed tomography (CT) scanning for assessing the resectability with curative intent in pancreatic and periampullary cancer. Cochrane Database Syst Rev. 2016;7:CD009323.

11. Durczynski A, Kumor A, Hogendorf P, Szymanski D, Grzelak P, Strzelczyk J. Preoperative high level of D-dimers predicts unresectability of pancreatic head cancer. World J Gastroenterol. 2014;20(36):13167-71.

12. Schlieman MG, Ho HS, Bold RJ. Utility of tumor markers in determining resectability of pancreatic cancer. Arch Surg. 2003;138(9):951-5 discussion 955-956.

13. Ellsmere J, Mortele K, Sahani D, Maher M, Cantisani V, Wells W, Brooks D, Rattner D. Does multidetector-row $C T$ eliminate the role of diagnostic laparoscopy in assessing the resectability of pancreatic head adenocarcinoma? Surg Endosc. 2005;19(3):369-73.

14. Gleisner AL, Assumpcao L, Cameron JL, Wolfgang CL, Choti MA, Herman JM Schulick RD, Pawlik TM. Is resection of periampullary or pancreatic adenocarcinoma with synchronous hepatic metastasis justified? Cancer. 2007:110(11):2484-92.

15. Hackert T, Niesen W, Hinz U, Tjaden C, Strobel O, Ulrich A, Michalski CW, Buchler MW. Radical surgery of oligometastatic pancreatic cancer. Eur J Surg Oncol. 2016:43(2):358-363.

16. Merkow RP, Bilimoria KY, Tomlinson JS, Paruch JL, Fleming JB, Talamonti MS, Ko CY, Bentrem DJ. Postoperative complications reduce adjuvant chemotherapy use in resectable pancreatic cancer. Ann Surg. 2014;260(2): $372-7$.

17. Gastinger I, Meyer F, Shardin A, Ptok H, Lippert H, Dralle H. Investigations on in-hospital mortality in pancreatic surgery: results of a multicenter observational study. Chirurg. 2018. https://doi.org/10.1007/s00104-018-0654-x.

18. Insulander J, Sanjeevi S, Haghighi M, Ivanics T, Analatos A, Lundell L, De Chiaro M, Andren-Sandberg A, Ansorge C. Prognosis following surgical bypass compared with laparotomy alone in unresectable pancreatic adenocarcinoma. Br J Surg. 2016;103(9):1200-8.

19. Stefanidis D, Grove KD, Schwesinger WH, Thomas CR Jr. The current role of staging laparoscopy for adenocarcinoma of the pancreas: a review. Ann Oncol. 2006;17(2):189-99.

20. Contreras CM, Stanelle EJ, Mansour J, Hinshaw JL, Rikkers LF, Rettammel R, Mahvi DM, Cho CS, Weber SM. Staging laparoscopy enhances the detection of occult metastases in patients with pancreatic adenocarcinoma. J Surg Oncol. 2009;100(8):663-9. 
21. Jimenez RE, Warshaw AL, Rattner DW, Willett CG, McGrath D, Fernandez-del Castillo C. Impact of laparoscopic staging in the treatment of pancreatic cancer. Arch Surg. 2000;135(4):409-14 discussion 414-405.

22. Glant JA, Waters JA, House MG, Zyromski NJ, Nakeeb A, Pitt HA, Lillemoe $K D$, Schmidt CM. Does the interval from imaging to operation affect the rate of unanticipated metastasis encountered during operation for pancreatic adenocarcinoma? Surgery. 2011;150(4):607-14.

23. Karabicak I, Satoi S, Yanagimoto H, Yamamoto T, Hirooka S, Yamaki S, Kosaka H, Inoue K, Matsui Y, Kon M. Risk factors for latent distant organ metastasis detected by staging laparoscopy in patients with radiologically defined locally advanced pancreatic ductal adenocarcinoma. J Hepatobiliary Pancreat Sci. 2016;23(12):750-755

24. Feldman MK, Gandhi NS. Imaging evaluation of pancreatic Cancer. Surg Clin North Am. 2016;96(6):1235-56.

25. Tamburrino D, Riviere D, Yaghoobi M, Davidson BR, Gurusamy KS. Diagnostic accuracy of different imaging modalities following computed tomography $(C T)$ scanning for assessing the resectability with curative intent in pancreatic and periampullary cancer. The Cochrane database of systematic reviews. 2016:9:CD011515.

26. Lavy R, Gatot I, Markon I, Shapira Z, Chikman B, Copel L, Halevy A. The role of diagnostic laparoscopy in detecting minimal peritoneal metastatic deposits in patients with pancreatic cancer scheduled for curative resection. Surgical laparoscopy, endoscopy \& percutaneous techniques. 2012;22(4): 358-60.

27. Sanjeevi S, Ivanics T, Lundell L, Kartalis N, Andren-Sandberg A, Blomberg J, Del Chiaro M, Ansorge C. Impact of delay between imaging and treatment in patients with potentially curable pancreatic cancer. Br J Surg. 2016;103(3): 267-75.

28. Raman SP, Reddy S, Weiss MJ, Manos LL, Cameron JL, Zheng L, Herman JM, Hruban RH, Fishman EK, Wolfgang CL. Impact of the time interval between MDCT imaging and surgery on the accuracy of identifying metastatic disease in patients with pancreatic cancer. AJR Am J Roentgenol. 2015; 204(1):W37-42.

29. Steen W, Blom R, Busch O, Gerhards M, Besselink M, Dijk F, Festen S. Prognostic value of occult tumor cells obtained by peritoneal lavage in patients with resectable pancreatic cancer and no ascites: a systematic review. J Surg Oncol. 2016;114(6):743-51.

30. Yamada S, Fujii T, Kanda M, Sugimoto H, Nomoto S, Takeda S, Nakao A, Kodera Y. Value of peritoneal cytology in potentially resectable pancreatic cancer. Br J Surg. 2013;100(13):1791-6.

31. Yoshioka R, Saiura A, Koga R, Arita J, Takemura N, Ono Y, Yamamoto J, Yamaguchi T. The implications of positive peritoneal lavage cytology in potentially resectable pancreatic cancer. World J Surg. 2012;36(9):2187-91.

32. Ta R, O'Connor DB, Sulistijo A, Chung B, Conlon KC. The role of staging laparoscopy in Resectable and borderline Resectable pancreatic Cancer: a systematic review and meta-analysis. Dig Surg. 2018. https://doi.org/10. $1159 / 000488372$.

33. Sell NM, Fong ZV, Del Castillo CF, Qadan M, Warshaw AL, Chang D, Lillemoe $\mathrm{KD}$, Ferrone $C R$. Staging laparoscopy not only saves patients an incision, but may also help them live longer. Ann Surg Oncol. 2018;25(4):1009-16.

34. Enestvedt CK, Mayo SC, Diggs BS, Mori M, Austin DA, Shipley DK, Sheppard BC, Billingsley KG. Diagnostic laparoscopy for patients with potentially resectable pancreatic adenocarcinoma: is it cost-effective in the current era? J Gastrointest Surg. 2008;12(7):1177-84.

35. Hennig R, Tempia-Caliera AA, Hartel M, Buchler MW, Friess H. Staging laparoscopy and its indications in pancreatic cancer patients. Dig Surg 2002;19(6):484-8.

36. Warshaw AL, Tepper JE, Shipley WU. Laparoscopy in the staging and planning of therapy for pancreatic cancer. Am J Surg. 1986;151(1):76-80.

37. De Rosa A, Cameron IC, Gomez D. Indications for staging laparoscopy in pancreatic cancer. HPB. 2016;18(1):13-20.

38. Maithel SK, Maloney S, Winston C, Gonen M, D'Angelica MI, Dematteo RP, Jarnagin WR, Brennan MF, Allen PJ. Preoperative CA 19-9 and the yield of staging laparoscopy in patients with radiographically resectable pancreatic adenocarcinoma. Ann Surg Oncol. 2008;15(12):3512-20.

39. Slaar A, Eshuis WJ, van der Gaag NA, Nio CY, Busch OR, van Gulik TM, Reitsma JB, Gouma DJ. Predicting distant metastasis in patients with suspected pancreatic and periampullary tumors for selective use of staging laparoscopy. World J Surg. 2011;35(11):2528-34.
40. Okada K, Kawai M, Tani M, Hirono S, Miyazawa M, Shimizu A, Kitahata Y, Yamaue $\mathrm{H}$. Predicting factors for unresectability in patients with pancreatic ductal adenocarcinoma. J Hepatobiliary Pancreatic Sci. 2014;21(9):648-53.

41. Kim YC, Kim HJ, Park JH, Park DI, Cho YK, Sohn Cl, Jeon WK, Kim BI, Shin JH. Can preoperative CA19-9 and CEA levels predict the resectability of patients with pancreatic adenocarcinoma? J Gastroenterol Hepatol. 2009;24(12): 1869-75.

42. Ong SL, Garcea G, Thomasset SC, Mann CD, Neal CP, Abu Amara M, Dennison AR, Berry DP. Surrogate markers of resectability in patients undergoing exploration of potentially resectable pancreatic adenocarcinoma. J Gastrointest Surg. 2008;12(6):1068-73.

\section{Ready to submit your research? Choose BMC and benefit from:}

- fast, convenient online submission

- thorough peer review by experienced researchers in your field

- rapid publication on acceptance

- support for research data, including large and complex data types

- gold Open Access which fosters wider collaboration and increased citations

- maximum visibility for your research: over $100 \mathrm{M}$ website views per year

At BMC, research is always in progress.

Learn more biomedcentral.com/submissions 